\title{
Enhanced Percutaneous Delivery of Methotrexate Using Micelles Prepared with Novel Cationic Amphipathic Material
}

This article was published in the following Dove Press journal: International Journal of Nanomedicine

\author{
Yun-Chun Zhao' \\ Hai-Li Zheng ${ }^{2}$ \\ Xiao-Rong Wang \\ Xiao-Ling Zheng' \\ Yue Chen' \\ Wei-Dong Fei ${ }^{1}$ \\ Yong-Quan Zheng' \\ Wen-Xi Wang ${ }^{2}$ \\ Cai-Hong Zheng' \\ 'Pharmacy Department, Zhejiang \\ University, Women's Hospital, School of \\ Medicine, Hangzhou, People's Republic of \\ China; ${ }^{2}$ College of Pharmaceutical \\ Science, Zhejiang University of \\ Technology, Hangzhou, People's Republic \\ of China
}

Correspondence: Cai-Hong Zheng Zhejiang University, Women's Hospital, School of Medicine, I Xueshi Road, Hangzhou 310006, People's Republic of China

Tel +86-057I-8999|730

Email chzheng@zju.edu.cn

Wen-Xi Wang

College of Pharmaceutical Science,

Zhejiang University of Technology, 18

Chaowang Road, Hangzhou 3100I4,

People's Republic of China

Tel +86-057I-88320320

Email yjw@zjut.edu.cn
Background: Methotrexate (MTX) is an antiproliferative drug widely used to treat inflammatory diseases and autoimmune diseases. The application of percutaneous administration is hindered due to its poor transdermal penetration. To reduce side effects and enhanced percutaneous delivery of MTX, novel methotrexate (MTX)-loaded micelles prepared with a amphiphilic cationic material, $N, N$-dimethyl-( $N^{\prime}, N^{\prime}$-di-stearoyl-1-ethyl)1,3-diaminopropane (DMSAP), was designed.

Materials and Methods: DMSAP was synthesized via three steps using simple chemical agents. $\mathrm{H}$ nuclear magnetic resonance and mass spectroscopy were used to confirm the successful synthesis of DMSAP. A safe and non-toxic phosphatidylcholine, soybean phosphatidylcholine (SPC), was added to DMSAP at different ratios to form P/D-micelles. Then, MTX-entrapped micelles (M/P/D-micelles) were prepared by electrostatic adsorption. The physicochemical properties and blood stability of micelles were examined thoroughly. In addition, the transdermal potential of the micelles was evaluated by permeation experiments. Results: In aqueous environments, DMSAP conjugates could self-assemble spontaneously into micelles with a low critical micelle concentration (CMC) of $0.056 \mathrm{mg} / \mathrm{mL}$. Stable, spherical MTX-entrapped micelles (M/P/D-micelles) with a size of 100-120 nm and high zeta potential of $+36.26 \mathrm{mV}$ were prepared. In vitro permeation studies showed that $\mathrm{M} / \mathrm{P} /$ D-micelles exhibited superior skin permeability and deposition of MTX in the epidermis and dermis compared with that of free MTX.

Conclusion: These special novel cationic M/P/D-micelles can enhance the permeability of MTX and are expected to be a promising percutaneous delivery system for therapy skin diseases. Keywords: $N N$-dimethyl-( $N^{\prime} N^{\prime}$-di-stearoyl-1-ethyl)1, 3-diaminopropane, methotrexate, micelle, percutaneous delivery

\section{Introduction}

Methotrexate (MTX) is the most frequently used antagonist of folic acid. It is an efficacious drug against psoriasis, rheumatism, melanoma and other types of cancer. ${ }^{1}$ MTX is usually administered via oral or parenteral routes. ${ }^{2}$ However, various side effects (stomatitis, ${ }^{3}$ mucosal ulceration, bone-marrow suppression, ${ }^{4}$ hepatic fibrosis/cirrhosis) ${ }^{5}$ can occur if a commercial MTX formulation is administered over a long period.

These drawbacks can be overcome by loading MTX into various percutaneous delivery systems, which have other advantages (including avoidance of first-pass elimination and improved treatment compliance from patients). ${ }^{6}$ MTX is a hydrophilic polar molecule (log partition coefficient $=-1.85$ ) that appears in 
the dissociated form at physiologic $\mathrm{pH}$ and has an average molecular weight of $454 \mathrm{Da}$. Its capacity for passive diffusion through lipophilic cuticles is limited. ${ }^{7}$

To overcome these limitations, researchers have employed several physical and chemical methods: sonophoresis and iontophoresis, ${ }^{8}$ chemical enhancers, ${ }^{9}$ liposomes, ${ }^{10}$ microneedles ${ }^{11,12}$ as well as solid and liquid -oil cores. ${ }^{13}$ To some extent, these physical and chemical methods can increase MTX enhancement through the skin, but some imperfections remain.

In the past decade, colloidal drug-delivery systems have been developed to enhance the absorption of a drug, release the drug in a controlled manner for a prolonged period of time and reduce offtarget toxicity of drugs. ${ }^{14-16}$ Various particles for transdermal delivery systems have been used: micelles, ${ }^{17}$ dendrimers, ${ }^{18}$ emulsomes ${ }^{19}$ and nanogels. ${ }^{20}$ Studies have suggested that copolymeric micelles can enhance the permeation and deposition of a drug, and reduce the drug distribution in the blood circulation system. $^{21-23}$

Micelles can enter the skin through three distinct pathways: (i) intercellular (through the lipid matrix occupying the intercellular spaces of keratinocytes); (ii) transcellular (through keratinocytes); (iii) transappendageal (across hair follicles, sebaceous glands and sweat glands). ${ }^{24}$ Permeation is dependent upon lipid composition, micelle size, and zeta potential. ${ }^{14}$ The positive charge of a micelle aids binding with negatively charged skin cells and hair follicles. ${ }^{25}$

Recently, positively charged surfactants ${ }^{26}$ have been used widely to solve the problem of poor transdermal passage of MTX through animal skin. Positively charged micelles have several favorable physicochemical and biologic properties that allow targeting to specific sites in vivo: ${ }^{27}$ nanoscale size suitable for drug delivery; structure (hydrophobic core and hydrophilic shell) that allows loading of hydrophilic drugs or protection of sensitive cargo; "tailored" architecture for sustained or controlled release. To enhance the efficiency of transdermal penetration and retention of MTX, we tried to use micelles formed by a novel positively charged material as a drug-delivery system to carry MTX across the skin (Figure 1). Within a hydrophilic head and two long hydrophobic tail, this positively charged material, DMSAP can be self-assembled into colloidal particles (micelles). The micelles were considered to enhance the solubility, permeability, retention and bioavailability of MTX and other drugs for a superior transdermal passage through the skin.

In the present study, soybean phosphatidylcholine (SPC) was added into DMSAP to prepare stable, MTX-entrapped micelles. The physicochemical properties of micelles were characterized in terms of critical micelle concentration (CMC), size, zeta potential, and entrapment efficiency (EE). Finally, the transdermal potential of the micelles was evaluated by permeation experiments through mice skin in vitro using Franz diffusion cells, which demonstrated that these micelles could be used to treat skin diseases.

\section{Materials and Methods \\ Materials}

SPC was purchased from Lipoid Co. Ltd. (Ludwigshafen am Rhein, Germany). HEPES buffer was obtained from Zeheng Biology Technology Co. Ltd. (Shanghai, China). MTX was purchased from Sigma-Aldrich (Saint Louis, MO, USA). Dimethylamine solution (40 wt. \% in $\mathrm{H}_{2} \mathrm{O}$ ), 1-Bromo-3-chloropropane, tetrabutylammonium bromide, and diethanolamine were obtained from Aladdin Industrial Corporation (Shanghai, China). Methanol was of analytical grade. All other chemicals were reagent grade and used as received. Water was double-distilled.

\section{DMSAP Synthesis}

The synthesis of DMSAP was divided into three steps using simple chemical agents (Figure 2). First, $N$, $\mathrm{N}$-dimethylaminochloropropane hydrochloride (DMAPC)
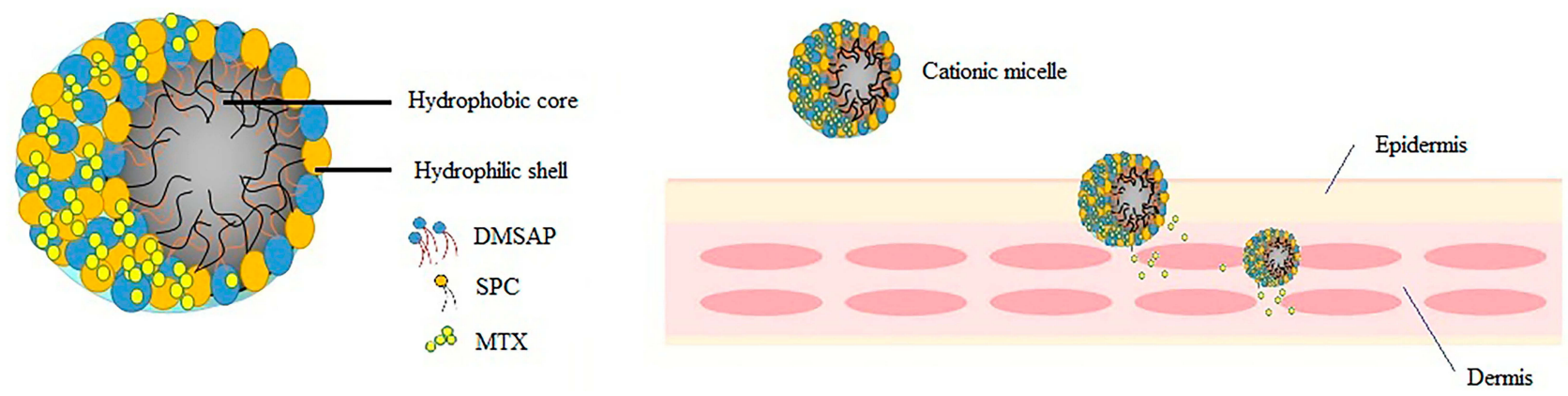

Figure I M/P/D-micelles transport in skin (schematic). 


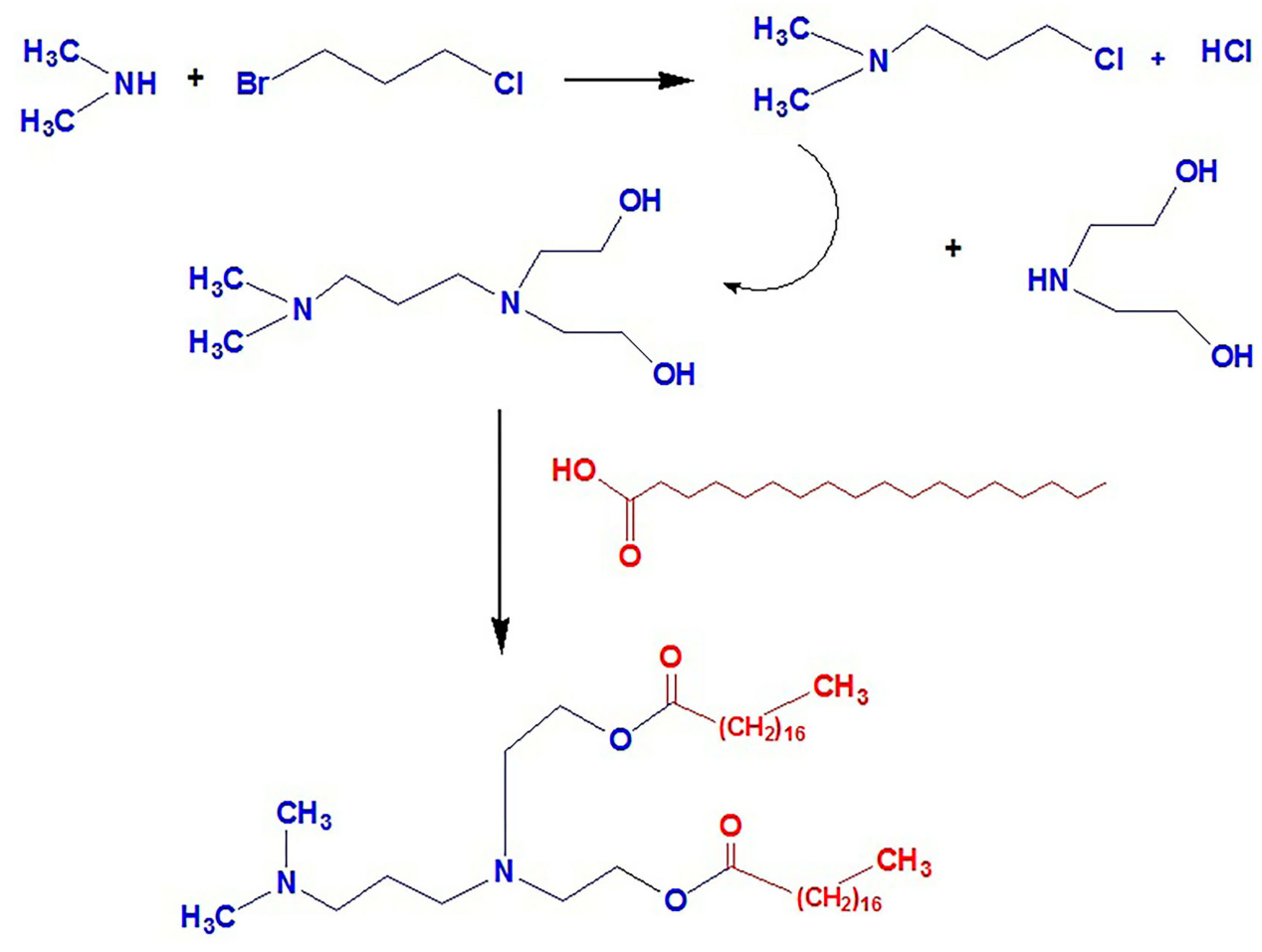

Figure 2 The synthesis of [[3-(dimethylamino) propyl] imino] -di-2,I- ethanediyl ester (DMSAP).

was synthesized by a substitution reaction as reported previously. ${ }^{28}$ Briefly, $42 \mathrm{~mL}$ of toluene, $16.5 \mathrm{~mL}$ of 1-bromo3-chloropropane, $20.25 \mathrm{~g}$ of dimethylamine solution (40 wt.\% in $\mathrm{H}_{2} \mathrm{O}$ ) and $0.6 \mathrm{~g}$ of tetrabutylammonium bromide were added to a three-mouthed flask containing a thermometer. Then, $9.18 \mathrm{~mL}$ of sodium hydroxide $\left(50 \%\right.$ in $\left.\mathrm{H}_{2} \mathrm{O}\right)$ was added dropwise into the mixture within $1 \mathrm{~h}$ at $35-40^{\circ} \mathrm{C}$; in the end, the reaction was carried out for $2 \mathrm{~h}$ at $40-45^{\circ} \mathrm{C}$.

The second product was ethanol 2,2'-[[3-(dimethylamino) propyl] imino] bis-(PDEA). Eight grams of DMAPC was dissolved in $200 \mathrm{~mL}$ of acetonitrile and mixed in $5.3 \mathrm{~mL}$ of diethanolamine in a three-mouth flask containing an agitator and a dropping funnel. Then, $23 \mathrm{~g}$ of $\mathrm{K}_{2} \mathrm{Co}_{3}$ was added to adjust the $\mathrm{pH}$. The reaction was allowed to proceed under the protection of nitrogen for 4 days at room temperature. The desired product was obtained through esterification according to a patent. ${ }^{29}$ Briefly, $3 \mathrm{~g}$ of octadecanoic acid and $2.5 \mathrm{~g}$ of dicyclohexylcarbodiimide were dissolved in $90 \mathrm{~mL}$ of chloroform for $1 \mathrm{~h}$ at room temperature. Then, $1 \mathrm{~mL}$ of PDEA was added to the mixture to react for $48 \mathrm{~h}$ at $60^{\circ} \mathrm{C}$. Finally, the reaction mixture was passed through a vacuum suction filter and then concentrated and purified in a silica-gel column with dichloromethane/methanol/petroleum ether at a 6:1:3 ratio. It was characterized by ${ }^{1} \mathrm{H}$ nuclear magnetic resonance (NMR) spectroscopy and mass spectroscopy (MS).

\section{Preparation of DMSAP Micelles (D-Micelles), Phosphatidylcholine D-Micelles (P/D-Micelles) and MTX-Loaded P/D-Micelles (M/P/ D-Micelles)}

D-micelles were prepared by reverse evaporation. ${ }^{30}$ Briefly, DMSAP (50 mg; $69.2 \mu \mathrm{mol}$ ) was dissolved in $12 \mathrm{~mL}$ of chloroform and then $4 \mathrm{~mL}$ of HEPES (20 mM) was added. A water/oil emulsion was formed stably by sonication for $30 \mathrm{~min}$. Then, the solvent was evaporated under a stream of argon gas for $30 \mathrm{~min}$. Hydration was undertaken in $6 \mathrm{~mL}$ of HEPES for $2.5 \mathrm{~h}$ at $37^{\circ} \mathrm{C}$, followed by sonication for $30 \mathrm{~min}$ using a probe-type sonicator. $\mathrm{P} /$ D-micelles at different ratios of SPC and DMSAP were prepared according to the method stated above.

$\mathrm{M} / \mathrm{P} / \mathrm{D}-$ micelles were prepared by electrostatic adsorption. ${ }^{31}$ MTX was dissolved in $\mathrm{NaOH}$ aqueous solution $(1 \mathrm{M})$ to obtain a concentration of $1 \mathrm{mg} / \mathrm{mL}$ and then diluted with HEPES. MTX and blank D-micelles were incubated in a water bath for $2 \mathrm{~h}$ at $50^{\circ} \mathrm{C} . \mathrm{P} / \mathrm{D}$-micelles and $\mathrm{M} / \mathrm{P} /$ D-micelles of different sizes or surface charges were controlled by the ratios of SPC and DMSAP.

\section{CMC Measurement}

Various concentrations of DMSAP containing pyrene $\left(6.0 \times 10^{-6} \mathrm{M}\right)$ were prepared $(0.002$ to $0.5 \mathrm{mg} / \mathrm{mL})$ by 
the addition of HEPES. Samples were sonicated for 0.5 h. The mixture solution was incubated in a dark room for 5 $\mathrm{h}$ at $30^{\circ} \mathrm{C}$. The emission spectrum of fluorescent pyrene was monitored by a fluorescence spectrometer (F-2500; Hitachi, Tokyo, Japan) at an excitation wavelength of $337 \mathrm{~nm}$. Pyrene emission was monitored at a wavelength range of $360-450 \mathrm{~nm}$.

\section{Characterization of P/D-Micelles and M/ P/D-Micelles}

\section{Particle Size, Zeta Potential and Morphology}

Micelles can exhibit a range of sizes and morphologies upon assembly of pure lipids or lipid mixtures suspended in an aqueous medium. ${ }^{27}$ The particle size and zeta potential of $\mathrm{P} / \mathrm{D}$-micelles and $\mathrm{M} / \mathrm{P} / \mathrm{D}$-micelles were measured using dynamic light scattering with a Zetasizer (3000HSA; Malvern Instruments, Malvern, UK). Each value of hydrodynamic diameter and zeta potential was measured in triplicate. The morphology of D-micelles and P/D-micelles was observed using a transmission electron microscope (JEM-1010; Jeol, Tokyo, Japan) operating at an acceleration voltage of $80 \mathrm{kV}$.

\section{Influence of lonic Strength and Bovine Serum Albumin (BSA)}

The influence of ionic strength upon hydrodynamic diameter was measured using a Zetasizer (ZS; Malvern Instruments). Samples were incubated with different ionic solutions of different ionic strengths. Sizes were measured at $25^{\circ} \mathrm{C}$ in triplicate and results presented as the mean \pm standard deviation. Magnesium sulfate $\left(\mathrm{MgSO}_{4}\right)$, sodium sulfate $\left(\mathrm{Na}_{2} \mathrm{SO}_{4}\right)$, calcium chloride $\left(\mathrm{CaCl}_{2}\right)$ and magnesium chloride $\left(\mathrm{MgCl}_{2}\right)$ were used as ionic solutions, and the ionic strength was $2 \mathrm{mM}$ to $40 \mathrm{mM}$. The same procedure was used to measure the influence of BSA (as a protein) upon hydrodynamic diameter.

\section{EE of M/P/D-Micelles}

The EE (\%) of M/P/D-micelles was measured by ultracentrifugation at $10^{5} \times \mathrm{g}$ for $6 \mathrm{~h}$ at $4^{\circ} \mathrm{C}$ and determined by ultraviolet (UV) spectrophotometry at $306 \mathrm{~nm}$. The experiment was carried out independently for three repeat samples per experimental group $(n=3)$. The EE of M/P/D-micelles was calculated using the following equation:

$$
\mathrm{EE} \%=(\mathrm{ND}-\mathrm{D}) / \mathrm{ND} \times 100
$$

where ND and D are the MTX concentration before and after centrifugation, respectively.

\section{Permeation in vitro}

Mice (20-25 g) housed in animal facilities of the department of pharmacology, Zhejiang University of Technology, were used for percutaneous absorption studies. The procedure was evaluated and approved by the ethical committee of university and all experiments were performed in accordance with the guidelines for the care and use of animals established by the Zhejiang University of Technology. Mice skins were used to be tested and abdominal hairs of mice were shaved using an electric razor after cervical dislocation executed before treatment. Abdominal skin was removed surgically and adherent subcutaneous fat cleaned carefully. Franz diffusion cells were set up on a skin-penetration apparatus (HDT6; Erweka, Hessen, Germany) equipped with six Franz cells. Each set of experiments was undertaken with three Franz diffusion cells $(n=3)$. The composition of MTX/DMSAP/SPC (in $\mathrm{mg}$ ) was 5/37.5/12.5, which ensured a ratio of MTX to total lipid of $1: 10$. One milliliter of M/P/D-micelles (MTX: $0.25 \mathrm{mg} / \mathrm{mL}$ ) was tested in the permeation experiment. The permeability of a pure MTX solution (MTX: $0.25 \mathrm{mg} / \mathrm{mL}$ ) was compared with that of an aqueous control solution containing the same amount of MTX. M/P/D-micelles and aqueous solution were applied to mice skin in the donor cell. One milliliter of the sample was extracted from the receptor compartment at $8,16,24.32,40,48$ and $56 \mathrm{~h}$, and replaced with the same volume of buffer solution at $37^{\circ}$ $\mathrm{C}$ to maintain a constant volume. At the end of the transdermal experiment $(56 \mathrm{~h})$, the MTX concentration in the skin and the receiving phase was analyzed by highperformance liquid chromatography (HPLC).

\section{HPLC of MTX}

Quantitative analyses of MTX were done by HPLC using a liquid chromatograph (LC-10AT; Shimadzu, Shiga, Japan), an auto-injector syringe pump (FCV10AL; Shimadzu) and an ultraviolet/visible (UV/vis) detector. An ODS $(5 \mu \mathrm{m}, 250 \times 4.6 \mathrm{~mm}$ ID) column was used for analyses at $35^{\circ} \mathrm{C}$. A mobile phase composed of phosphate buffer ( $\mathrm{pH} 7.4) /$ methanol (81/19 v/ v) was used, and the flow rate was set at $0.8 \mathrm{~mL} / \mathrm{min}$. The sample injection volume was $20 \mu \mathrm{L}$, and MTX was detected by an UV-spectrophotometer (UV-2450, Shimadzu) operating at $306 \mathrm{~nm}$ with a retention time of $8.2 \mathrm{~min}$. 


\section{Statistical Analyses}

Experiments were carried out three or more times independently. One-way ANOVA and the Student's two-tailed $t$-test were used to analyze significant differences between experimental groups. Prism 5 (GraphPad, San Diego, CA, USA) was employed for statistical analyses. $\mathrm{P}<0.05$ was considered significant.

\section{Results and Discussion Characterization of DMSAP}

Cationic materials containing a "double tail" with two saturated alkyl chains show high stability for micelle formation. ${ }^{32}$ Researchers have found that cationic materials with different lengths of alkyl chains elicit different effects on micelle formation. Paecharoenchai et $\mathrm{al}^{33}$ found that long carbon chains increased the solubility of cationic lipids in niosomes. Furthermore, niosomes-C18 showed a higher zeta potential than niosomes-C14. It is expected that longer alkyl chains will have stronger hydrophobic interactions with SPC lipids to produce a tighter Polymerhybridized liposome (PHL) lipid bilayer compared with shorter alkyl chains. ${ }^{34}$

Originally, DMSAP was synthesized for use as a softening agent in the textile industry, and not considered for use in drugdelivery systems. Typically, cationic (and neutral) lipids are used for transdermal delivery of MTX because of the polyanionic nature of MTX. With a hydrophilic head and double hydrophobic tails (the same properties as surfactants), DMSAP can be used for micelle formation in aqueous solution. DMSAP carries a large positive charge, so it can be used for the formation of cationic micelles.

In the present study, the synthetic route of DMSAP was quite simple because commonly available reagents were reacted under a warm condition, but the strategy was innovative. The final polymeric DMSAP was purified and characterized unambiguously by ${ }^{1} \mathrm{H}$ NMR spectroscopy (Figure 3 ). The characteristic peaks of DMSAP $(1.65,2.2,2.2-2.3,2.35,2.55$ and $2.75 \mathrm{ppm}$ ) were observed clearly. MS demonstrated the molecular weight of the product to be $723.7\left[\mathrm{M}+\mathrm{H}^{+}\right]$ (Figure 4).

\section{Self-Assembly of D-Micelles}

DMSAP has two hydrophobic tails and a hydrophilic head, so it could form micelles in the aqueous phase. The selfassembly behavior of DMSAP in neutral aqueous media was examined using pyrene as a fluorescence probe. Fluorescence spectra displayed no significant changes at low concentrations of DMSAP. However, above a threshold concentration, DMSAP aggregated automatically to form micelles by intramolecular and/or intermolecular associations in an aqueous solution: this is defined as the CMC.

It is generally accepted that hydrophobic pyrene molecules are located preferably in the hydrophobic micro-domains of micelles rather than in the aqueous phase. This scenario results in variations of photophysical characteristics, especially the change in the $\mathrm{I}_{374} / \mathrm{I}_{385}$ ratio. The CMC of DMSAP was $0.056 \mathrm{mg} / \mathrm{mL}\left(7.7 \times 10^{-5} \mathrm{~mol} / \mathrm{L}\right)$ (Figure 5). This value is much lower than that of low-molecular-weight surfactants

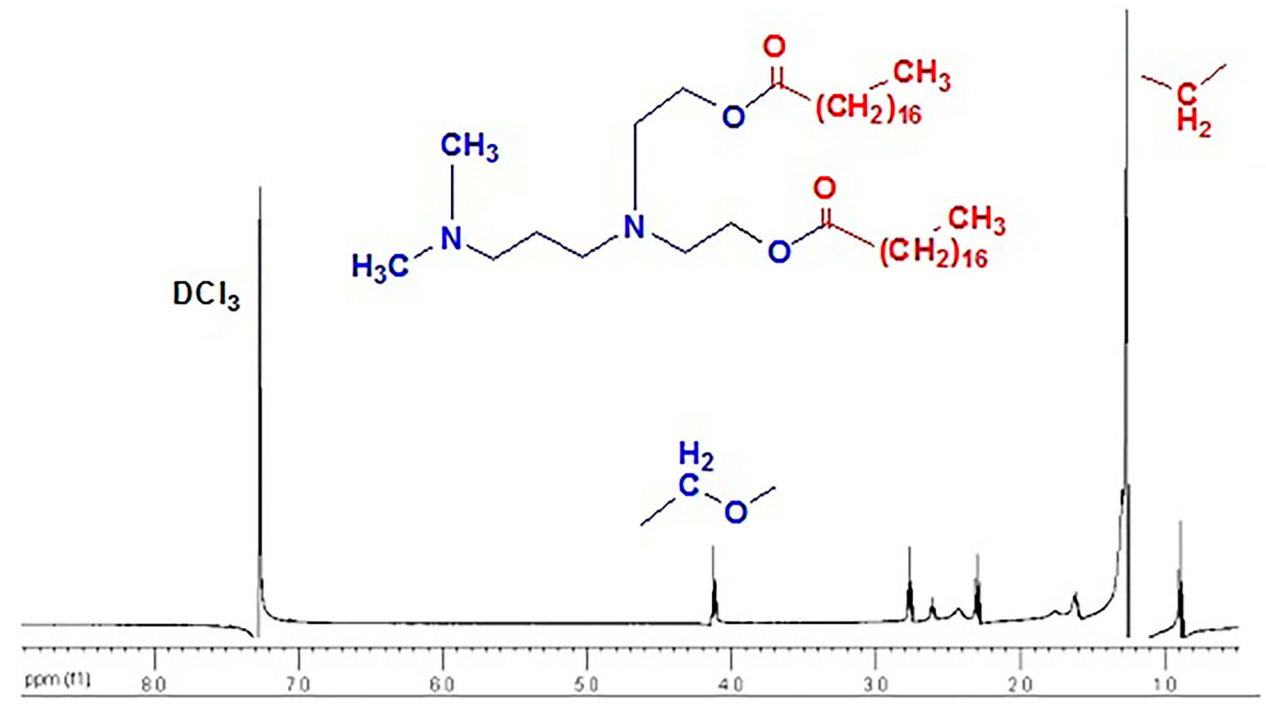

Figure 3 ' $\mathrm{H}$ NMR spectra of DMSAP ( $\mathrm{CDCl}_{3}$; internal standard, tetramethylsilane). 


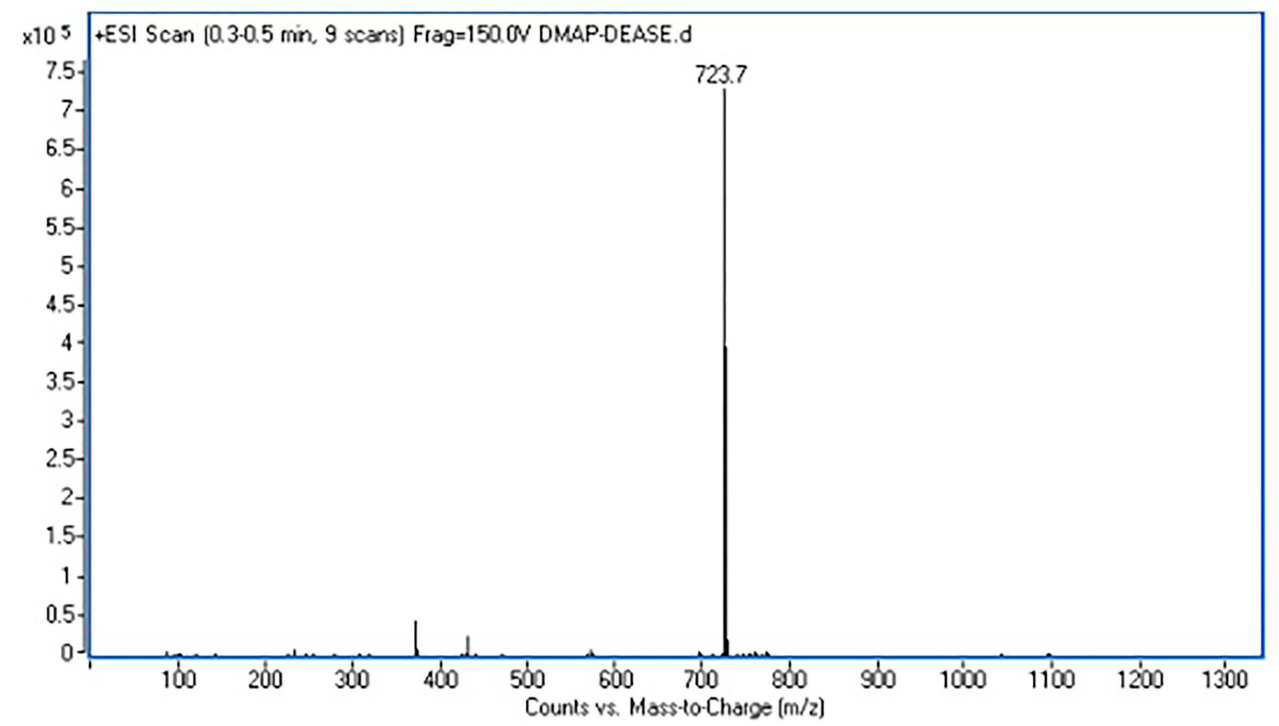

Figure 4 Mass spectrum of DMSAP.

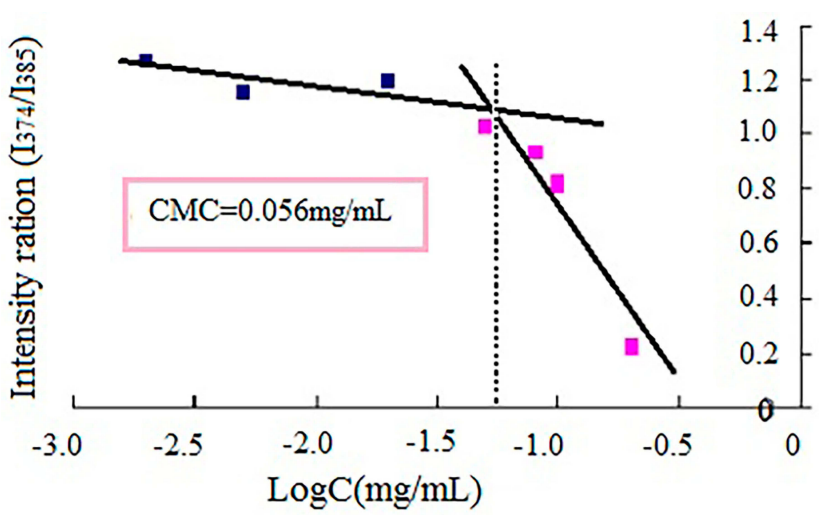

Figure 5 The $\mathrm{I}_{374} / \mathrm{I}_{385}$ ratio of pyrene fluorescence as a function of DMSAP concentration.

such as sodium dodecyl sulfate $\left(6.9 \times 10^{-3} \mathrm{~mol} / \mathrm{L}\right)$ and $\mathrm{C}_{17} \mathrm{H}_{35}$ COOK $\left(4.5 \times 10^{-4} \mathrm{~mol} / \mathrm{L}\right){ }^{35}$ The $\mathrm{CMC}$ is an important factor for polymeric micelles as drug-delivery vehicles. A low CMC is desired to avoid micelle disassociation by body fluids, thereby leading to good thermodynamic stability under highly diluted conditions. $^{36}$

\section{Characterization of D-Micelles, P/D-Micelles and M/P/D-Micelles} General Features

After preliminary studies, reverse-phase evaporation was used to prepare micelles because this method can lead to the formation of uniform micelles compared with that using other methods. ${ }^{35}$ The appearance without mini-probe sonography was turbid (Figure 6A). After ultrasound, smaller and more uniform micelles with small blue "rays" were
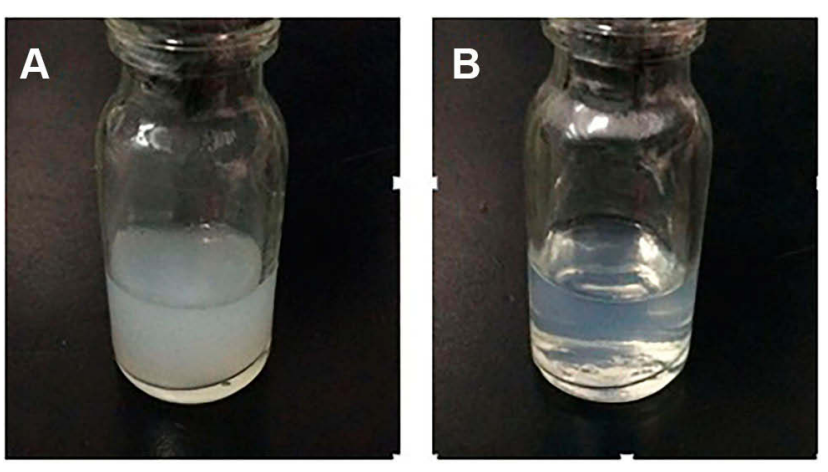

Figure 6 DMSAP micelles at a SPC/DMSAP ratio of I:3 were sonicated for 10 min (A: before sonication; $B$ : after sonication).

obtained (Figure 6B). We hypothesized that use of sonography could reduce the diameter of micelles and make micelles more stable. Meanwhile, we demonstrated that micelles could be stored at $4^{\circ} \mathrm{C}$ for $\geq 15$ days. The mean hydrodynamic diameter of D-micelles and P/D-micelles was $(\sim 120 \mathrm{~nm})$ with a low polydispersity index (0.25). Obviously, having different ratios of DMSAP and SPC would not influence the diameter of $\mathrm{P} / \mathrm{D}$-micelles. Addition of MTX to D-micelles would produce precipitation of large particles, but not in $\mathrm{P} / \mathrm{D}$-micelles. Therefore, $\mathrm{P} / \mathrm{D}$-micelles were used for loading MTX in subsequent experiments.

The diameter of P/D-micelles showed a slight increase when MTX was entrapped (Figure 7A). The zeta potential of $\mathrm{P} / \mathrm{D}$-micelles and D-micelles was about $+30 \mathrm{mV}$ (Figure 7B). A similar zeta potential of micelles helps to prolong the circulation time in the bloodstream because the adsorption of non-specific proteins is suppressed. The zeta potential of $\mathrm{P} /$ 


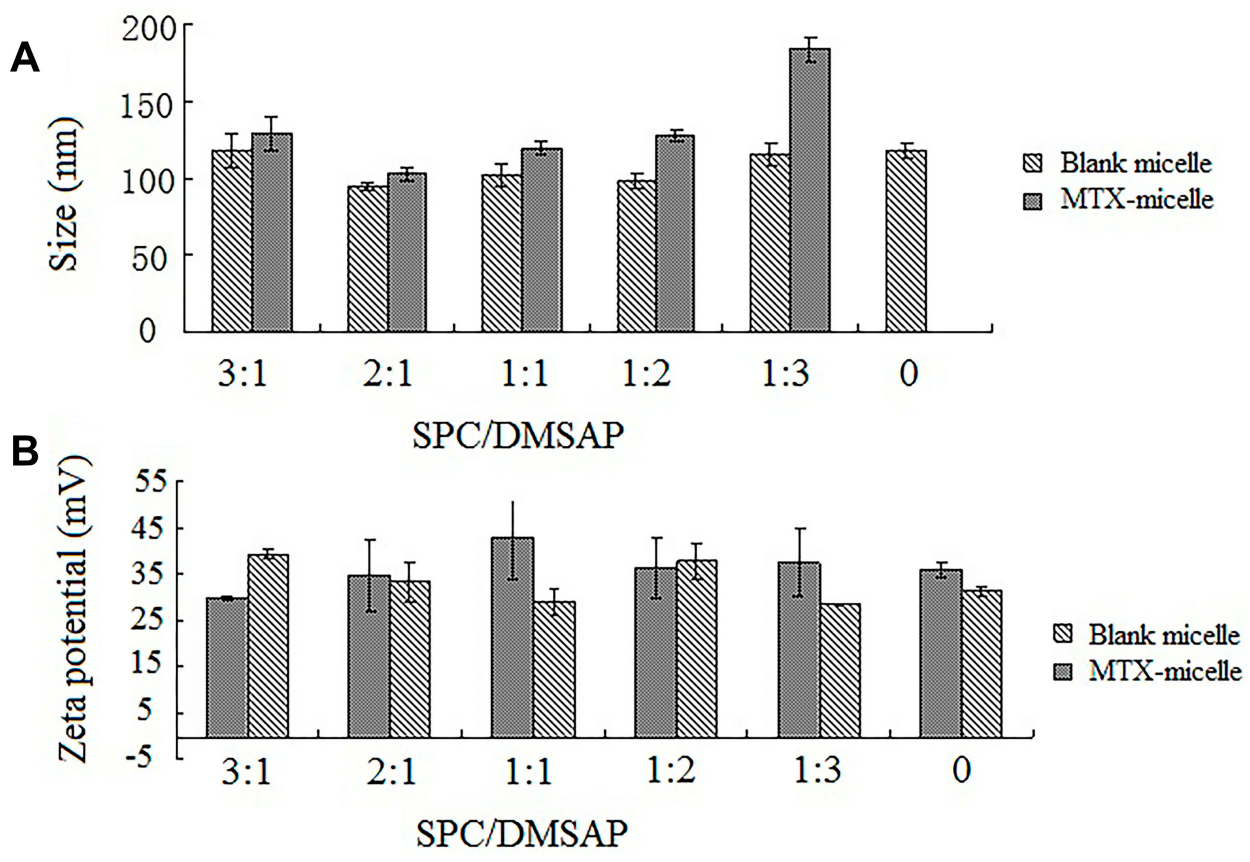

Figure 7 Size and zeta potential of micelles prepared at different ratios of SPC and DMSAP. Compared with blank and MTX-in the different ratios of SPC and DMSAP (mean $\pm S D ; n=3)$.

D-micelles and D-micelles was similar because the structure of SPC and DMSAP carried positive charges. If one positive charge on DMSAP is neutralized by a negative charge, another positive charge on SPC is supplied.

The morphology of D-micelles and P/D-micelles was measured by transmission emission microscopy. The differences in their shapes were obvious: D-micelles were cylindrical (Figure 8A) whereas P/D-micelles were spherical (Figure 8B). It has been reported that spherical particles can be formed more readily than non-spherical particles. ${ }^{37}$
We hypothesized that the static charges of DMSAP and SPC would attract each other, and repel each other when SPC was added, and that the structure of DMSAP would be rearranged. Furthermore, use of surfactant agents such as SPC in drug-delivery systems might mask or reduce the undesirable effects of cationic lipids. ${ }^{32}$

\section{Influence of lonic Strength and BSA}

Inorganic ions can compress the thickness of ion clouds and reduce the repulsion between ions, which may affect micelle

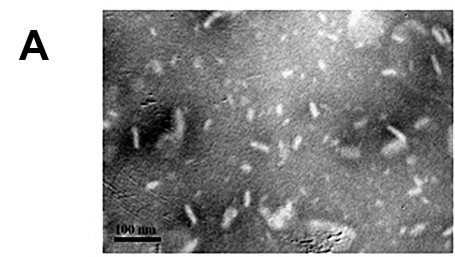

B

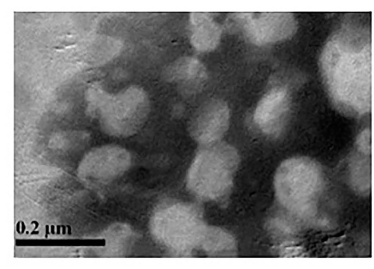

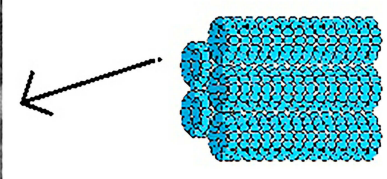

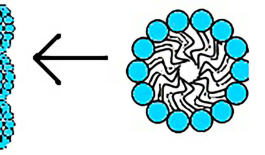

Cylindrial

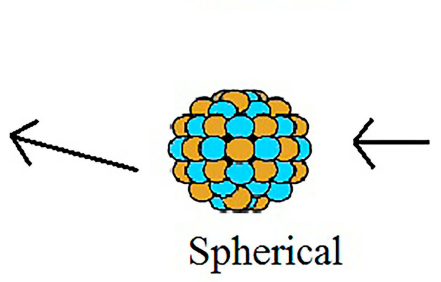

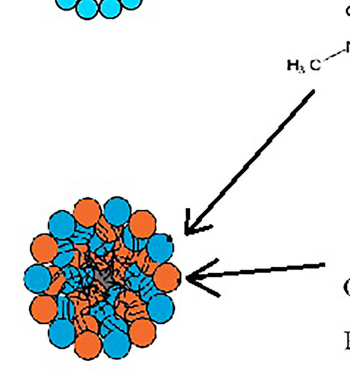

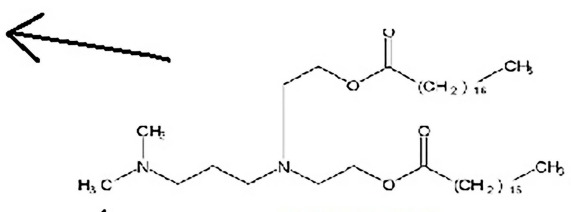

DMSAP

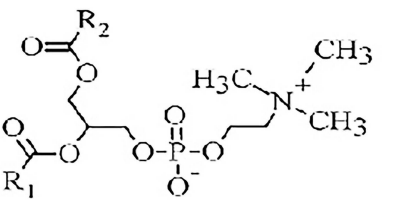

SPC

Figure 8 TEM of D-micelles and P/D-micelles. A: micelles self-assembled by $50 \mathrm{mg}$ of DMSAP in $10 \mathrm{~mL}$ of HEPES and after dilution with distilled water. B: Micelles formed by $75 \mathrm{mg}$ of DMSAP and $25 \mathrm{mg}$ SPC in the same way as A. DMSAP self-assembled to be form cylindrical micelles. Mixed lipids formed spherical micelles. 


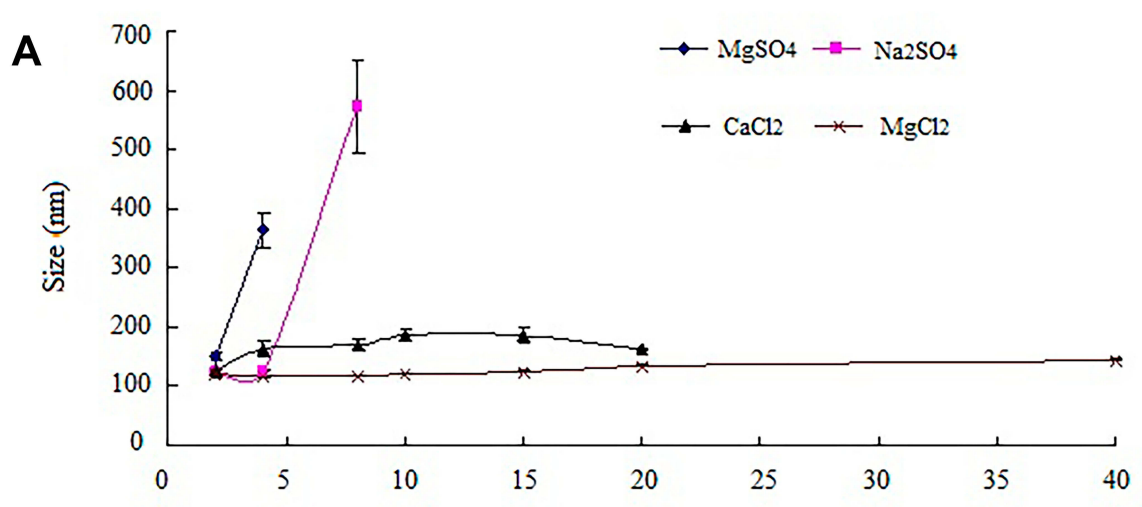

Ionic Concentration (mM)

B

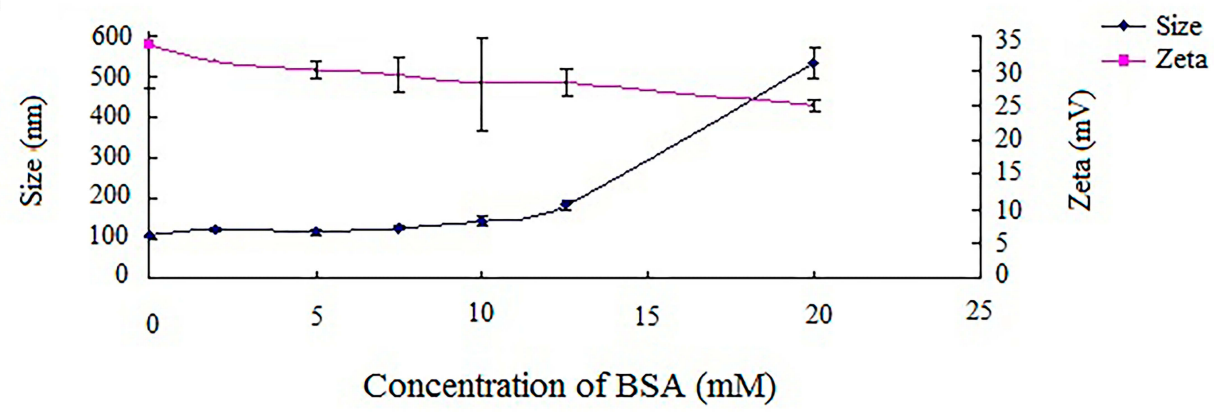

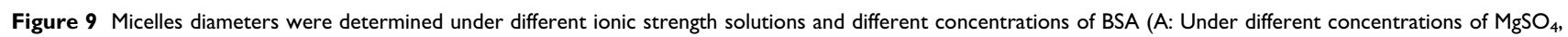
$\mathrm{Na}_{2} \mathrm{SO}_{4}, \mathrm{CaCl}_{2}$ and $\mathrm{MgCl}_{2}$ in 2, 4, 8, 10, 15, 20 and $40 \mathrm{mM}$; B: Size and zeta potentials under different concentrations of BSA in 0, 2, 5, 7.5, I0 and I2.5 mM.) .

formation. For non-ionic surfactants, hydrophobic groups can "salt out" or "salt in". Salting out results in a lower CMC of surfactants; salting in has the opposite effect. Inorganic ions can also cause alterations to non-ionic surfactants; salting out makes the surfactant associate readily, leading to the formation of larger micelles and leads to a turbid solution. ${ }^{38}$

We also assessed the effects of dispersion media (distilled water and culture medium). P/D-micelles could be stable in distilled water and HEPES (20 mM in water) but they precipitated in phosphate-buffered solution (PBS). We postulate that the highly charged ions of PBS may be a critical factor influencing micelle size. $\mathrm{MgSO}_{4}, \mathrm{Na}_{2} \mathrm{SO}_{4}$, $\mathrm{CaCl}_{2}$ and $\mathrm{MgCl}_{2}$ were added to the same micelle solution. We found that $\mathrm{MgSO}_{4}$ and $\mathrm{Na}_{2} \mathrm{SO}_{4}$ had a considerable influence on the size if the solution concentration was $>3$ $\mathrm{mM}$ (Figure 9A). Conversely, $\mathrm{CaCl}_{2}$ and $\mathrm{MgCl}_{2}$ had little effect on micelle size. These data suggested that micelles with positive charges would attract the double-charged negative ions present in solutions. Conversely, this micelle solution would not be attracted by $\mathrm{Cl}^{-}, \mathrm{Na}^{+}$or $\mathrm{Mg}^{2+}$ (which are present in blood at high concentrations) and so such micelles would be safe carriers to use in vivo. ${ }^{39}$
BSA was used to test the influence of serum proteins in blood on the size and zeta potential of micelles. Increasing the BSA concentration from 2.5
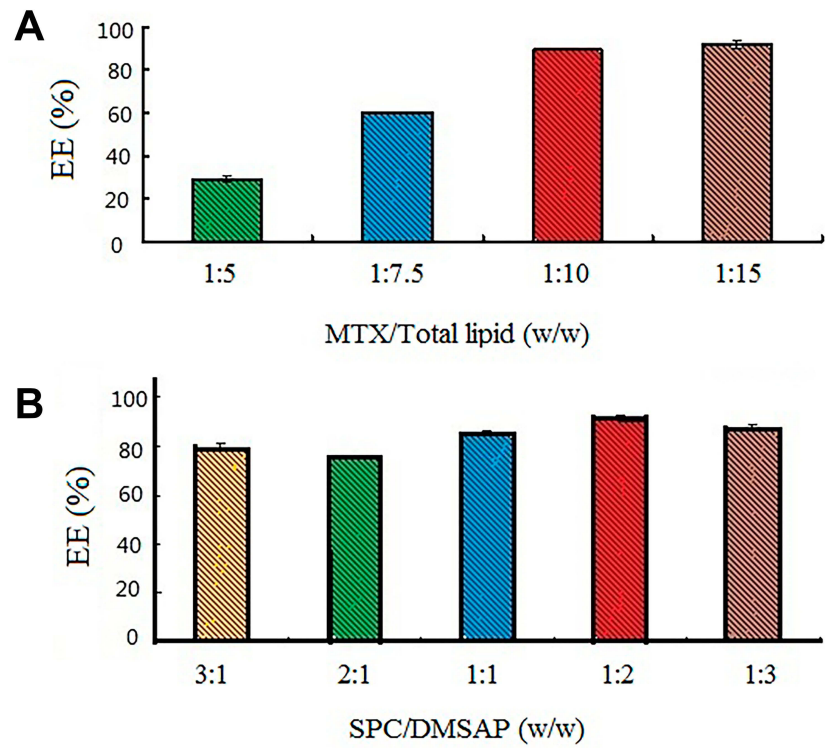

Figure 10 Efficiency of MTX entrapment in micelles using different ratios of MTX/ total lipids and SPC/DMSAP. A: The ratio of MTX to total lipids was 1:5, I:7.5, I:10 and I:I5. B: The ratio of SPC to DMSAP was 3:I, 2:I, I:I, I:2 and I:3. 


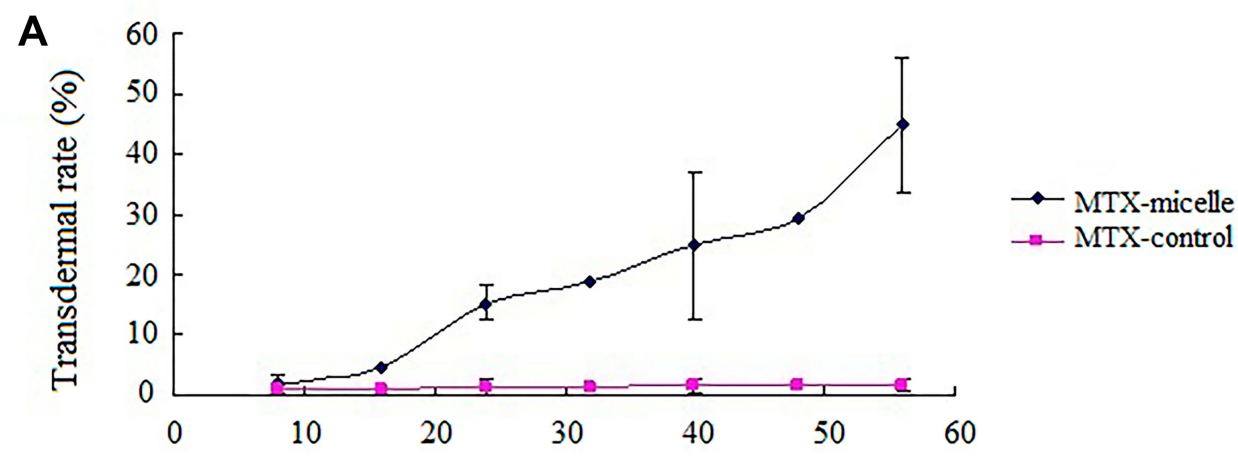

Time (h)

$\mathbf{B}$

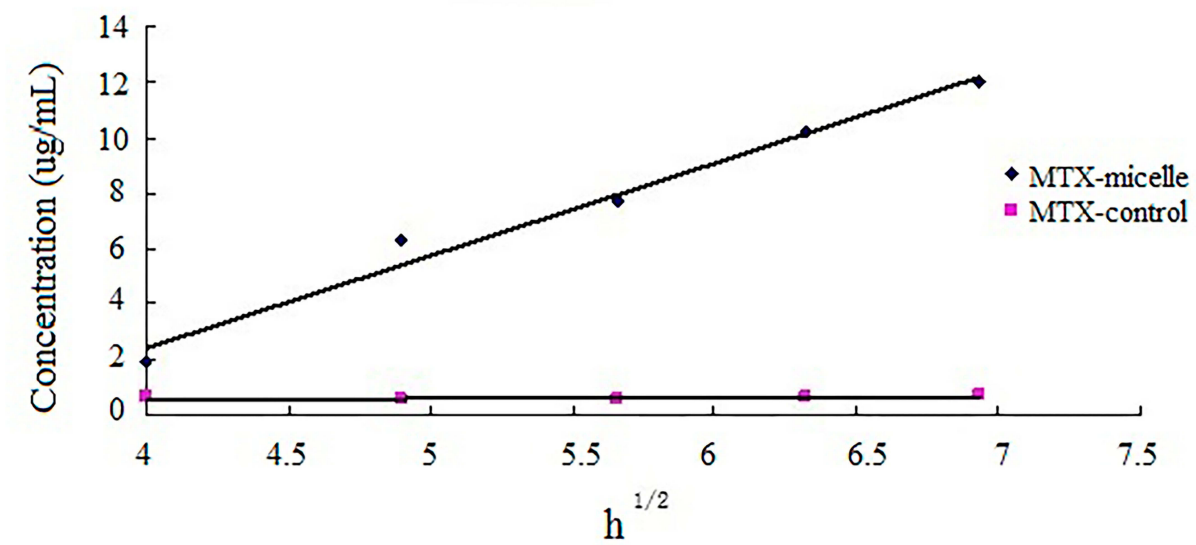

C

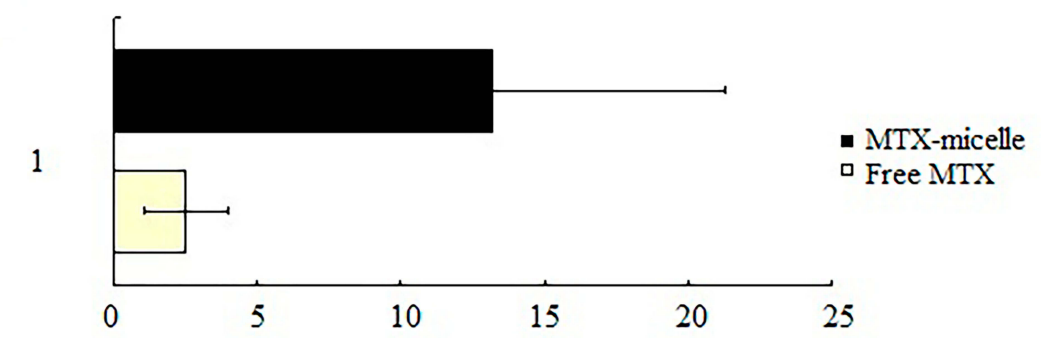

Figure I I Volume of MTX permeated across and retained in the mice skin. A: The relationship between the MTX percentage permeated across mice skin and time. B: Linear fitting of MTX volume that permeated across mice skin and time ${ }^{1 / 2}$ as micelles or not as micelles. C: Relationship between the MTX percentage retained in mice skin as micelles or not as micelles.

$\mathrm{mM}$ to $12.5 \mathrm{mM}$ resulted in a gradual increase in size and a gradual decrease in zeta potential, whereas the particle size increased significantly with a further increase in concentration (Figure 9B). A BSA concentration of $12.5 \mathrm{mM}$ is much higher than the concentration of serum in human blood $(160 \mathrm{~g} / \mathrm{L})$. An increasing concentration of BSA reduces the frequency of protein transport between water and micelles, thereby leading to slower nucleation rates and larger particles. $^{40}$ 


\section{EE of MTX-Entrapped Micelles}

The EE of MTX entrapped in micelles was measured by ultracentrifugation and determined by UV-spectrophotometry at $306 \mathrm{~nm}$. The EE was up to $91.50 \pm 1.02 \%$ when the weight ratio of SPC and DMSAP was $<1: 2$. The EE of MTX was increased upon MTX addition. This finding may have been due to more positive charges on DMSAP providing more attraction to MTX through electrostatic incorporation (Figure 10A). Furthermore, the long lipid chains of DMSAP result in considerable van der Waals' attraction, which promotes strong cohesion and results in stable micelles with low drug leakage. ${ }^{38}$ We demonstrated that increasing the amount of MTX could also increase the EE when the ratio of MTX to total lipid was 1:10. The high loading of MTX in micelles may have been due to two main reasons. First, MTX had a negative charge in the drug-loading environment ( $\mathrm{pH} 7.4)$; the $\mathrm{pKa}$ of MTX was 3.8, 4.8 and 5.6, which induced an electrostatic attraction between MTX and the protonated cationic amino moiety of DMSAP ( $\mathrm{pKa}=9.47$ ) in micelles. Second, hydrogen bonding might have been present between the amino groups in micelles and -COO groups in MTX molecules at $\mathrm{pH}$ 7.4. Therefore, many MTX molecules could be attached to micelles. ${ }^{41}$ Dramatically, it cannot be formed as micelles when mixed MTX solution with D-micelle. This finding may have been because the morphology of D-micelles was cylindrical; aggregation of D-micelles was accelerated by MTX. The EE of MTX was increased considerably (78.66\%) compared with that reported in niosomes. ${ }^{40}$ However, we found that micelles prepared with different ratios of SPC and DMSAP had little effect on the EE of MTX, and there was no significant difference $(\mathrm{P}>0.05)$ (Figure 10B).

\section{Permeation of M/P/D-Micelles Across Mice Skins in vitro}

Franz diffusion cells have been used as model barriers to assess MTX penetration in the skin in vitro. ${ }^{42}$ The abdominal skin of mice was chosen because it is very similar to human skin with respect to morphology and function. The potential of micelles for transdermal delivery of MTX was investigated over 56 $\mathrm{h}$ (Figure 11A). After $56 \mathrm{~h}$, the amount of MTX permeated through the skin was $44.81 \pm 11.22 \%$, whereas for free MTX it was 1.59 $\pm 0.51 \%$. There was a significant difference between $\mathrm{M} / \mathrm{P} /$ D-micelles and free MTX $(\mathrm{P}<0.01)$. This result suggested that MTX-entrapped micelles might adapt to physiologic conditions and enhance the percutaneous delivery of MTX to mice skin.

Moreover, a good linear relationship of M/P/D-micelles $\left(\mathrm{R}^{2}\right.$ 0.98) was found between the concentration of MTX diffused across the mice skin and time ${ }^{1,2}$ based on the Higuchi equation (Figure 11B). The slope of M/P/D-micelles $\left(\mathrm{k}=3.33 \mu \mathrm{g} / \mathrm{mLh}^{1,2}\right)$ was much higher than that for the MTX-free solution $(\mathrm{k}=0.02 \mu \mathrm{g} /$ $\left.\left(\mathrm{mLh}^{1,2}\right)\right)$, which further confirmed the higher permeation rate of $\mathrm{M} / \mathrm{P} / \mathrm{D}-$ micelles across the mice skin.

Another advantage of $\mathrm{M} / \mathrm{P} / \mathrm{D}$-micelles was the increased drug accumulation on the dermis and cuticle layer. Increased skin deposition of the drug is conducive to drug permeation of skin and has a role in local or systemic treatment. Micelles increased the drug deposition in the dermis and cuticle of mice skin (Figure 11C). Skin deposition of M/P/D-micelles was $13.18 \pm 8.11 \%$, whereas in the control group it was 2.53 $\pm 1.44 \%$. These data indicated that copolymeric micelles can enhance the permeation and deposition of a drug.

\section{Conclusions}

DMSAP, a faint-yellow product with high purity, was synthesized. P/D-micelles containing SPC (a lipid used safely and widely in pharmaceutics) were formed. $\mathrm{P} /$ D-micelles of uniform size (100-120 nm), positive charge of about $+30 \mathrm{mV}$ and spherical morphology were very stable in vivo (as indicated by assays on ionic strength and BSA) with an EE of $>90 \%$. Evaluation of skin permeation in vitro demonstrated that $\mathrm{M} / \mathrm{P} / \mathrm{D}$-micelles could pass through skin more readily than MTX aqueous solution. Overall, these novel cationic micelles could be carriers for MTX and permit transdermal delivery of MTX.

\section{Acknowledgments}

This work was supported financially by the National Natural Science Foundation of China, General Program (81802630, 81802587, 81873838) and Public Welfare Technology Research Project of Zhejiang Province (LGF18H300003).

\section{Disclosure}

The authors report no conflicts of interest in this work.

\section{References}

1. Tran NTT, Wang T, Lin C, Tai Y. Synthesis of methotrexate-conjugated gold nanoparticles with enhanced cancer therapeutic effect. Biochem Eng J. 2013;78:175-180. doi:10.1016/j.bej.2013.04.017

2. Yamasaki SC, Mendes MT, Alponti RF, Silveira PF. Efficacy of parenteral administration of bee venom in experimental arthritis in the rat: a comparison with methotrexate. Toxicon. 2015;98:75-88. doi:10.1016/j.toxicon.2015.02.016

3. Jinbu Y, Kashiwazaki A, Ozawa M, Inoue E, Kusama M, Demitsu T. Bilateral oral lichenoid lesions on the buccal mucosa due to methotrexate: report of two cases. J Oral Maxillofac Surg Med Pathol. 2015;27(1):102-105. doi:10.1016/j.ajoms.2014.04.005 
4. Gulgun M, Erdem O, Oztas E, et al. Proanthocyanidin prevents methotrexate-induced intestinal damage and oxidative stress. Exp Toxicol Pathol. 2009;62(2):109-115. doi:10.1016/j.etp.2009.02.120

5. Bilasy SE, Essawy SS, Mandour MF, Ali EAI, Zaitone SA. Myelosuppressive and hepatotoxic potential of leflunomide and methotrexate combination in a rat model of rheumatoid arthritis. Pharmacol Rep. 2015;67(1):102-114. doi:10.1016/j.pharep.2014.08.009

6. Uchino T, Matsumoto Y, Murata A, Oka T, Miyazaki Y, Kagawa Y. Transdermal delivery of flurbiprofen from surfactant-based vesicles: particle characterization and the effect of water on in vitro transport. Int J Pharm. 2014;464(1-2):75-84. doi:10.1016/j.ijpharm.2013.12.051

7. Javiera AM, Vicente GJ. Passive and iontophoretic transdermal penetration of chlorpromazine. Pharm Dev Technol. 2008;13(4):101-107.

8. Nguyen Hiep X, Banga Ajay K. Electrically and ultrasonically enhanced transdermal delivery of methotrexate. Pharmaceutics. 2018;10(3):70-78.

9. Javadzadeh Y, Hamishehkar H. Enhancing percutaneous delivery of methotrexate using different types of surfactants. Colloids Surf $B$ Biointer. 2010;82(2):422-426. doi:10.1016/j.colsurfb.2010.09.015

10. Alam Z, Salman QO, Hyung-Seo K, Ji-Hye C, Hoo-Seong K, Jin-Ki $\mathrm{K}$. Improved skin permeation of methotrexate via nanosized ultradeformable liposomes. Int $J$ Nanomedicine. 2016;11:3813-3824. doi:10.2147/IJN.S109565

11. Nguyen Hiep X, Banga Ajay K. Delivery of methotrexate and characterization of skin treated by fabricated PLGA microneedles and fractional ablative laser. Pharm Res. 2018;35(3):68. doi:10.1007/ s11095-018-2369-6

12. Abla Mehtab J, Ayyappa C, Conor O, Banga Ajay K. Transdermal delivery of methotrexate for pediatrics using silicon microneedles. Ther Deliv. 2013;4(5):543-551. doi:10.4155/tde.13.24

13. Zhang Y, Wu Z, Zhang K, Zhao J, Ye B, Feng N. An in vitro and in vivo comparison of solid and liquid-oil cores in transdermal aconitine nanocarriers. J Pharm Sci. 2014;103(11):3602-3610. doi:10.1002/jps. 24152

14. Kesharwani SS, Kaur S, Tummala H, Sangamwar AT. Overcoming multiple drug resistance in cancer using polymeric micelles. Expert Opin Drug Deliv. 2018;15(11):1127-1142. doi:10.1080/ 17425247.2018 .1537261

15. Kesharwani SS, Kaur S, Tummala H, Sangamwar AT. Multifunctional approaches utilizing polymeric micelles to circumvent multidrug resistant tumors. Colloids Surf B. 2019;173:581-590. doi:10.1016/j.colsurfb.2018.10.022

16. Pratik M, Sunny K, Fadoua EK, Kesharwani Siddharth S, Hemachand T. Hydrophobically modified inulin as an amphiphilic carbohydrate polymer for micellar delivery of paclitaxel for intravenous route. Int $J$ Pharm. 2016;500(1-2):32-41. doi:10.1016/j. ijpharm.2016.01.005

17. Ren J, Fang Z, Yao L, et al. A micelle-like structure of poloxamer-methotrexate conjugates as nanocarrier for methotrexate delivery. Int $J$ Pharm. 2015;487(1-2):77-86. doi:10.1016/j. ijpharm.2015.04.014

18. Zhen-Hua L, Qian-Fen Z, Yan-Chao L, et al. Polyamidoamine dendrimer conjugated chitosan nanoparticles for the delivery of methotrexate. Carbohydr Polym. 2013;98(1):1173-1178. doi:10.1016/j.carbpol.2013.07.021

19. Paliwal R, Paliwal SR, Mishra N, Mehta A, Vyas SP. Engineered chylomicron mimicking carrier emulsome for lymph targeted oral delivery of methotrexate. Int J Pharm. 2009;380(1):181-188. doi:10.1016/j.ijpharm.2009.06.026

20. Chen Y, Zhu D, Xiong X, Liu J, Zhang C. Magnesium oil enriched transdermal nanogel of methotrexate for improved arthritic joint mobility, repair, and reduced inflammation. $J$ Microencapsul. 2020;37(1):77-90. doi:10.1080/02652048.2019.1694086

21. Feilong Z, Zhimei S, Yi W, Hongmei X, Li Z, Runliang F. Transdermal delivery of curcumin-loaded supramolecular hydrogels for dermatitis treatment. J Mater Sci Mater Med. 2019;30(1):11. doi:10.1007/s10856-018-6215-5
22. Aa AO, El-Say Khalid M, Aljaeid Bader M, Badr-Eldin Shaimaa M, Ahmed Tarek A. Optimized vinpocetine-loaded vitamin E D- $\alpha$ tocopherol polyethylene glycol 1000 succinate-alpha lipoic acid micelles as a potential transdermal drug delivery system: in vitro and ex vivo studies. Int $J$ Nanomedicine. 2019;14:33-43. doi:10.2147/IJN.S187470

23. Sintov Amnon C, Levy Haim V, Igor G. Continuous transdermal delivery of L-DOPA based on a self-assembling nanomicellar system. Pharm Res. 2017;34(7):1459-1468. doi:10.1007/s11095017-2162-y

24. Desai P, Patlolla RR, Singh M. Interaction of nanoparticles and cell-penetrating peptides with skin for transdermal drug delivery. Mol Membr Biol. 2010;27(7):247-259. doi:10.3109/09687688.20 10.522203

25. Sheelarani B, Karunanithi P, Dash S. Effect of valency of cation on micellization behaviour of pluronic mixed micelle F127 and L64. Chem Phys Lett. 2020;739.

26. Teixeira RS, Cova TFGG, Silva SMC, et al. Novel serine-based gemini surfactants as chemical permeation enhancers of local anesthetics: A comprehensive study on structure-activity relationships, molecular dynamics and dermal delivery. Eur J Pharm Biopharm. 2015;93:205-213. doi:10.1016/j.ejpb.2015.02.024

27. Silva SMC, Hu L, Sousa JJS, Pais AACC, Michniak-Kohn BB. A combination of nonionic surfactants and iontophoresis to enhance the transdermal drug delivery of ondansetron $\mathrm{HCl}$ and diltiazem $\mathrm{HCl}$. Eur J Pharm Biopharm. 2012;80(3):663-673. doi:10.1016/j.ejpb.2011.11.010

28. Qu J, Lu W. On the synthesis of N,N-dimethylaminochloropropane hydrochloride [J]. J Shaoxing Univ. 2010;7(30):29-31.

29. Imada H, Sasaki H, Yasumasu T. Diester diamine compounds, intermediates thereof, method for their preparation, and softening agents. [JP,06-340598,A].1994.

30. Knudsen KB, Northeved H, Pramod Kumar EK, et al. In vivo toxicity of cationic micelles and liposomes. Nanomedicine. 2015;11 (2):467-477. doi:10.1016/j.nano.2014.08.004

31. Yu B, Tang C, Yin C. Enhanced antitumor efficacy of folate modified amphiphilic nanoparticles through co-delivery of chemotherapeutic drugs and genes. Biomaterials. 2014;35(24):6369-6378. doi:10.1016/ j.biomaterials.2014.04.095

32. Grijalvo S, Alagia A, Puras G, Zárate J, Pedraz JL, Eritja R. Cationic vesicles based on non-ionic surfactant and synthetic aminolipids mediate delivery of antisense oligonucleotides into mammalian cells. Colloids Surf B Biointer. 2014;119:30-37. doi:10.1016/j.colsurfb.2014.04.016

33. Paecharoenchai O, Niyomtham N, Leksantikul L, et al. Nonionic surfactant vesicles composed of novel spermine-derivative cationic lipids as an effective gene carrier in vitro. AAPS PharmSciTech. 2014;15(3):722-730. doi:10.1208/s12249-014-0095-x

34. Park S, Lee E, Kim JW, Kim YJ, Han SH, Kim J. Polymer-hybridized liposomes anchored with alkyl grafted poly(asparagine). J Colloid Interface Sci. 2011;364(1):31-38. doi:10.1016/j.jcis.2011.07.046

35. Eloy JO, de Souza MC, Petrilli R, Barcellos JPA, Lee RJ, Marchetti JM. Liposomes as carriers of hydrophilic small molecule drugs: strategies to enhance encapsulation and delivery. Colloids Surf B Biointer. 2014;123:345-363. doi:10.1016/j.colsurfb.2014.09.029

36. Zhao Y, Zheng C, Zhang L, Chen Y, Ye Y, Zhao M. Knockdown of STAT3 expression in SKOV3 cells by biodegradable siRNA-PLGA/ CSO conjugate micelles. Colloids Surf $B$ Biointer. 2015;127:155-163. doi:10.1016/j.colsurfb.2015.01.034

37. Caldorera-Moore M, Guimard N, Shi L, Roy K. Designer nanoparticles: incorporating size, shape and triggered release into nanoscale drug carriers. Expert Opin Drug Deliv. 2010;7(4):479-495. doi:10.1517/17425240903579971

38. Chen WY, Hsu CH, Huang JR, Tsai ML, Chen RH. Effect of the ionic strength of the media on the aggregation behaviors of high molecule weight chitosan. J Polym Res. 2011;18:6. doi:10.1007/ s10965-010-9543-9 
39. Dustin S, Yaming J, Laaser Jennifer E, Lodge Timothy P, Reineke Theresa M. Tuning cationic block copolymer micelle size by $\mathrm{pH}$ and ionic strength. Biomacromolecules. 2016;17(9):2849-2859. doi:10.1021/ acs.biomac.6b00654

40. Moghaddam B, Ali MH, Wilkhu J, et al. The application of monolayer studies in the understanding of liposomal formulations. Int J Pharm. 2011;417(1):235-244. doi:10.1016/j.ijpharm.2011.01.020

41. Roya S, Sepideh R, Hamed H. Smart thermo/pH responsive magnetic nanogels for the simultaneous delivery of doxorubicin and methotrexate. Int J Pharm. 2015;487(1-2):274-284. doi:10.1016/j. ijpharm.2015.04.051
42. Abdelbary AA, AbouGhaly MHH. Design and optimization of topical methotrexate loaded niosomes for enhanced management of psoriasis: application of Box-Behnken design, in-vitro evaluation and in-vivo skin deposition study. Int J Pharm. 2015;485 (1-2):235-243. doi:10.1016/j.ijpharm.2015.03.020

\section{Publish your work in this journal}

The International Journal of Nanomedicine is an international, peerreviewed journal focusing on the application of nanotechnology in diagnostics, therapeutics, and drug delivery systems throughout the biomedical field. This journal is indexed on PubMed Central, MedLine, CAS, SciSearch ${ }^{\mathbb{R}}$, Current Contents ${ }^{\mathbb{R}} /$ Clinical Medicine, $^{-}$
Journal Citation Reports/Science Edition, EMBase, Scopus and the Elsevier Bibliographic databases. The manuscript management system is completely online and includes a very quick and fair peer-review system, which is all easy to use. Visit http://www.dovepress.com/ testimonials.php to read real quotes from published authors. 